\title{
Potencial Espeleoturístico das grutas do Circuito do Pião, Parque Estadual do lbitipoca (MG)
}

\author{
Cave Tourism potential of the Pião Circuit caves, State Park of \\ Ibitipoca (MG, Brazil)
}

\section{Bruno Diniz Costa, Ricardo Eustáquio Fonseca Filho, Heros Augusto Santos Lobo}

\begin{abstract}
RESUMO: O Parque Estadual do Ibitipoca (MG) é conhecido por suas cachoeiras e cursos d'água com coloração peculiar, bem como diversas cavernas turísticas e um potencial espeleológico a ser explorado. Neste contexto, torna-se necessário avaliar o potencial espeleoturístico das grutas abertas à visitação, a fim de atualizar as informações e percepções sobre sua conservação. A pesquisa realizada avaliou o potencial espeleoturístico das grutas do Circuito do Pião (Monjolinho, Viajantes e Pião), considerando suas fragilidades intrínsecas e potencialidades de uso. Assim, foi possível identificar os fatores condicionantes e limitantes à visitação turística nas três cavernas, apresentando resultados que podem contribuir com a gestão do parque. A interpretação dos resultados sugere a revisão da possibilidade de visitação da gruta do Pião, a limitação do uso público da gruta do Monjolinho e apresenta um alto potencial espeleoturístico para a gruta dos Viajantes, a qual necessita de intervenções de manejo que contribuam para o ordenamento da visitação turística.
\end{abstract}

PALAVRAS-CHAVE: Espeleoturismo; Cavernas Turísticas; Unidades de Conservação; Parque; Conservação do Patrimônio.

ABSTRACT: The Ibitipoca State Park (MG, Brazil) is known for its waterfalls and streams with peculiar coloring, as well as several tourist caves and a speleological potential to be explored. In this context, it is necessary to assess the speleotourist potential of its show caves, in order to analyze their conservation. The research carried out evaluated the speleotourist potential of the caves of the Pião Circuit (Monjolinho, Viajantes and Pião), considering their intrinsic weaknesses and possibilities for tourist use. Thus, it was possible to identify the conditioning and limiting factors to tourist visitation in these caves, presenting results that can contribute to the management of the park. The interpretation of the results suggests the review on the Pião cave, the limitation of the public use of the Monjolinho cave and has a high speleotouristic potential for the Travelers' Cave, which, even so, needs management interventions that contribute to the ordering of tourist visitation. The interpretation of the results suggests a revision of the possibility of visiting the Pião cave, the limitation of the public use of the Monjolinho cave and has a high speleotourist potential for the Viajantes cave, which requires management interventions that contribute to the organization of the tourist visitation.

KEYWORDS: Cave Tourism; Show Caves; Natural Protected Areas; Park; Heritage Conservation. 


\section{Introdução}

O crescente processo de urbanização das cidades e suas consequências na vida dos cidadãos estão entre os fatores que levam ao aumento do número de pessoas que buscam ambientes naturais como forma de alívio da movimentação intensa do cotidiano (MTUR, 2010; RUSCHMANN, 2016). Também como fruto da evolução na dinâmica de consumo da vida urbana, a oferta turística se estabeleceu a partir de diferentes segmentos turísticos que visam a promoção de atividades em áreas naturais, como o ecoturismo, o geoturismo (OSTANELLO et al., 2013) e o espeleoturismo (MARRA, 2001; LOBO et al., 2008a).

Estes segmentos são difundidos majoritariamente em Unidades de Conservação que, por sua vez, possuem o papel de proteger a natureza e, dentro do possível, conciliar a conservação com as atividades humanas sustentáveis (BRASIL, 2000). Entretanto, existem lacunas nas políticas públicas que tratam da conservação do patrimônio natural, principalmente no caso das cavernas, podendo resultar em deficiências na gestão das Unidades de Conservação (LOBO et al., 2008a). No caso do Parque Estadual do Ibitipoca (PEIB), o modelo de visitação é ainda mais alarmante no que tange a conservação das cavernas, tendo em vista a contínua multiplicação do número de pessoas que visitam o parque (LADEIRA et al., 2007). Este aspecto levantou ainda mais preocupações em função do acordo firmado entre o Instituto Estadual de Florestas (IEF) e o Ministério Público Estadual em 2019, aumentando o limite de visitação diário de 600 para 1.000 visitantes (IEF, 2019). A preocupação advém da ausência de estudos de capacidade de suporte das cavernas, bem como de um plano de manejo específico para seu uso público.

Diante destas considerações, realizou-se uma pesquisa com o objetivo de avaliar o potencial espeleoturístico das grutas do Circuito do Pião, como forma de identificar seu real potencial de atratividade turística e apontar os impactos decorrentes da visitação atual. As cavernas visitadas do PEIB apresentam alto grau de depredação e degradação, que são percebidos visualmente através de pichações, dejetos humanos, lixos, danos à vegetação do entorno e ao solo. Associado ao constante aumento de visitantes no parque, identificou-se a necessidade de avaliar as reais possibilidades de uso público nas grutas, além de contribuir para seus respectivos Planos de Manejo Espeleológico, a fim de ordenar a visitação nestes ambientes.

\section{Referencial teórico: Espeleoturismo}

O homem possui relação intrínseca com o ambiente cavernícola. Diversos vestígios líticos e ósseos, pinturas rupestres e o uso do fogo comprovam a antiga e estreita relação do homem com o subterrâneo. Vestígios ósseos de hominídeos encontrados em cavernas concluíram que a espécie humana teve início no continente africano (CERVANTES, 2011).

Embora esta relação ancestral de necessidade venha de tempos remotos, na atualidade as cavernas exercem outras influências sobre os seres humanos. Esta nova concepção, permeada por uma concepção de necessidade de contato com a natureza (DIEGUES, 2001), se evidencia pelo turismo - neste caso, especificamente o espeleoturismo: a visitação turística de cavernas. Lobo (2014, p.71) define o espeleoturismo como: 
Um segmento turístico que busca atingir de forma equilibrada a conservação das cavidades naturais, a conscientização e satisfação de todos os envolvidos no processo turístico e o desenvolvimento econômico local. Utiliza para tanto o patrimônio espeleológico, aproveitando as particularidades do ambiente por meio de propostas de diferenciação mercadológica.

Por serem ambientes extremamente frágeis e peculiares, as cavernas necessitam de uma atenção singular no planejamento turístico, tanto para manutenção da integridade física do visitante, quanto para sua conservação. Segundo Lobo et al. (2008a), embora a fragilidade deste ambiente justifique uma especial atenção quanto aos mecanismos reguladores que contribuam para conciliar o uso sustentável com a conservação, poucas leis e diretrizes versam diretamente sobre o tema.

Essa discussão é ainda mais emergente, se analisarmos a realidade do PEIB. Considerando que um serviço guiado não profissionalizado já pode comprometer as experiências dos visitantes, a inexistência deste tipo de serviço pode ser muito mais determinante para o aumento dos impactos oriundos de ações antrópicas, além da ausência da transmissão de informações relevantes que abordam o contexto em que a UC está inserida, resultando num modelo de visitação questionável sob a ótica da conservação dos recursos naturais.

\section{Caracterização da Área de Pesquisa}

A criação do Parque Estadual do Ibitipoca (PEIB) se deu pela lei 6.126, de 04 de julho de 1973, englobando territórios dos municípios de Lima Duarte e Santa Rita do Ibitipoca (MINAS GERAIS, 1973). Seu ambiente é composto por afloramentos quartzíticos e vegetação diferenciada em função da altitude, resultando em uma composição singular de sua paisagem. Entre os elementos atrativos para a visitação, destacam-se as águas com coloração de chá, as escarpas, os mirantes, as trilhas e o objeto do presente estudo, as cavernas. O PEIB possui diversas cavernas já catalogadas em seu interior, sendo que a visitação turística é permitida em nove grutas, a saber: Cruzeiro, Monjolinho, Pião, Coelhos, Fugitivos, Moreiras, Três Arcos, Viajantes e na Ponte de Pedra.

Devido a singularidade do carste da Serra de lbitipoca, deve-se atentar ao modelo de visitação adotado pelo parque. A circulação dos visitantes autoguiados aos atrativos levanta questionamentos sobre a eficácia do modelo para a conservação dos atributos do parque e para a própria segurança dos visitantes. Atualmente, o parque passa por análises que servirão de base para a implementação dos Planos de Manejo Espeleológico (PMEs) nas grutas já abertas à visitação e eventuais grutas que sejam descobertas após trabalhos de prospecção espeleológica.

Dados históricos apontam que em 1988, a visitação total no parque foi de quase 8.000 visitantes. Na década de 1990, o crescimento da visitação foi vertiginoso, chegando ao total aproximado de 50.000 pessoas em 1999 (LADEIRA et al. (2007). Após os anos 2000, a visitação variou bastante, conforme ilustram os dados cedidos pela gestão do PEIB (Figura 1). 


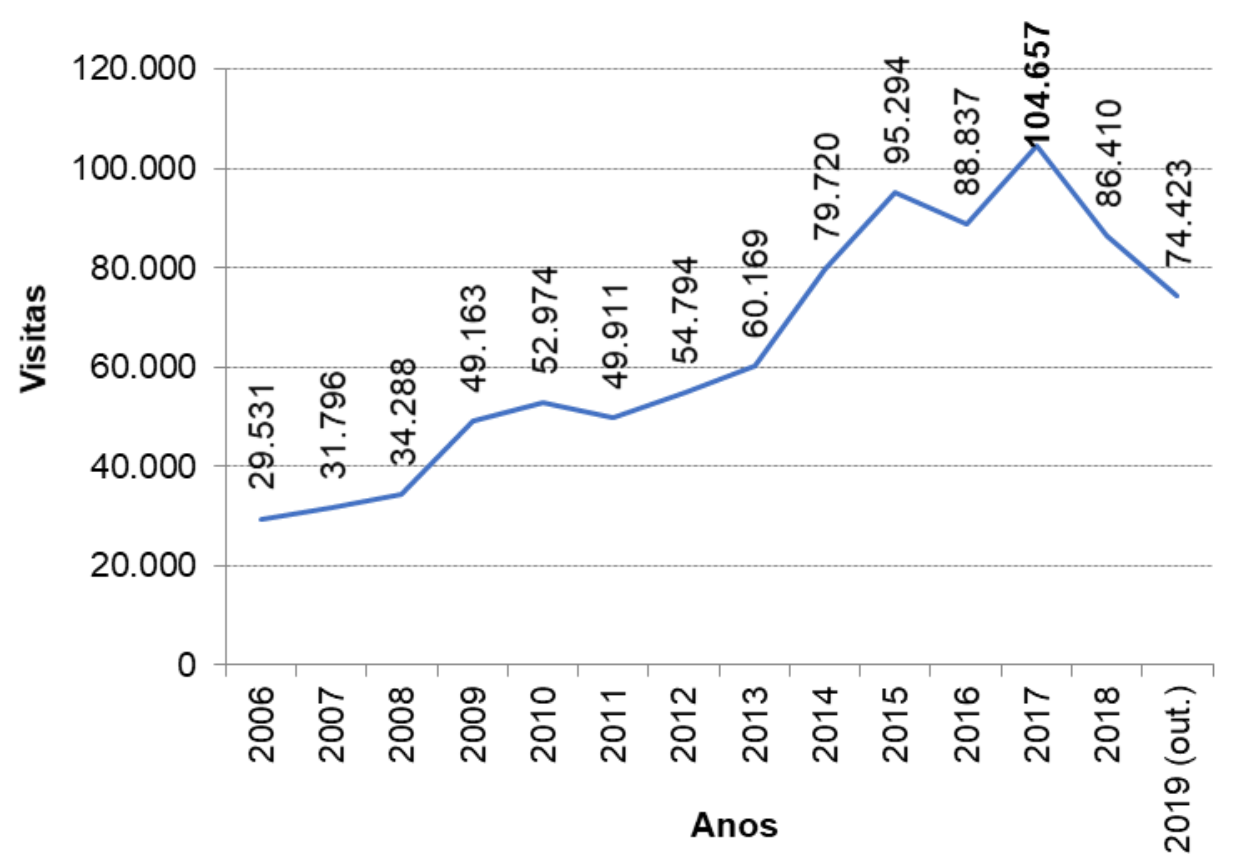

Figura 1: Média anual de visitantes entre o período de 2007-2019.

Figure 1: Annual average of visitors between 2007-2019 periods.

Fonte: gestão do PEIB.

Source: PEIB management data.

Observa-se que a partir de 2012, a visitação foi sempre superior aos 50 mil anuais, com um pico de quase 105 mil visitantes em 2017. Este aumento na visitação, aliado ao modelo de visitação sem a obrigatoriedade do acompanhamento de guias ou monitores e a falta de um comportamento adequado de parte dos visitantes, ampliou também os impactos observados no interior das cavernas. Problemas como pichações, vandalismos e disposição de lixo. Ladeira et al. (2007, p.1.092) trata dos impactos no parque, afirmando que:

O aumento da visitação em áreas naturais consorciadas com fragilidade de habitats, como é o caso do PElb, causa impactos ambientais negativos, tanto físicos (compactação do solo, processos erosivos, ruídos), bióticos (afugentamento da fauna, coleta ilegal de material) quanto antrópicos, pois um número elevado de visitantes causa desconforto não somente espacial, como também logístico (dificuldade de estacionamento, filas nos restaurantes). Esses impactos poderiam ser evitados ou diminuídos com algumas propostas de manejo adaptadas para a realidade ambiental da unidade em questão.

Exemplos destes impactos são ilustrados nas fotografias na Gruta dos Coelhos, com presença de pichações (Figura 2) e resíduos (Figura 3). Considerando este contexto e os problemas evidenciados, a análise do potencial espeleoturístico foi realizada nas cavernas com uso público da área denominada como Circuito do Pião: as grutas do Pião, dos Viajantes e Monjolinho (Figura 4). 

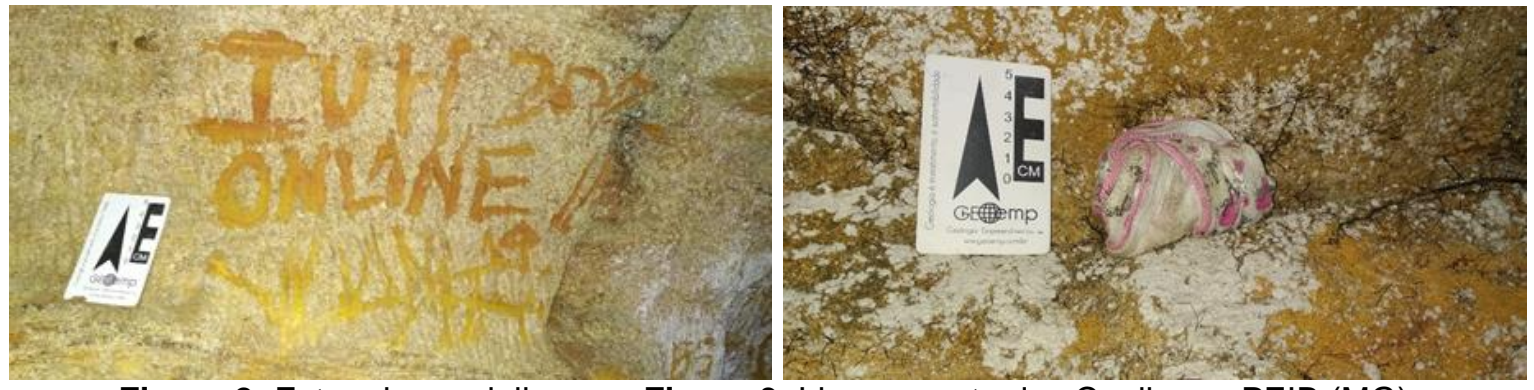

Figura 2: Fotos de vandalismo; e Figura 3: Lixo na gruta dos Coelhos - PEIB (MG).

Figures 2: Photos of vandalism; and Figure 3: Trash in Coelhos cave - PEIB (MG, Brazil).

Crédito: Gabriel Lourenço (2019).

Credits: Gabriel Lourenço (2019).

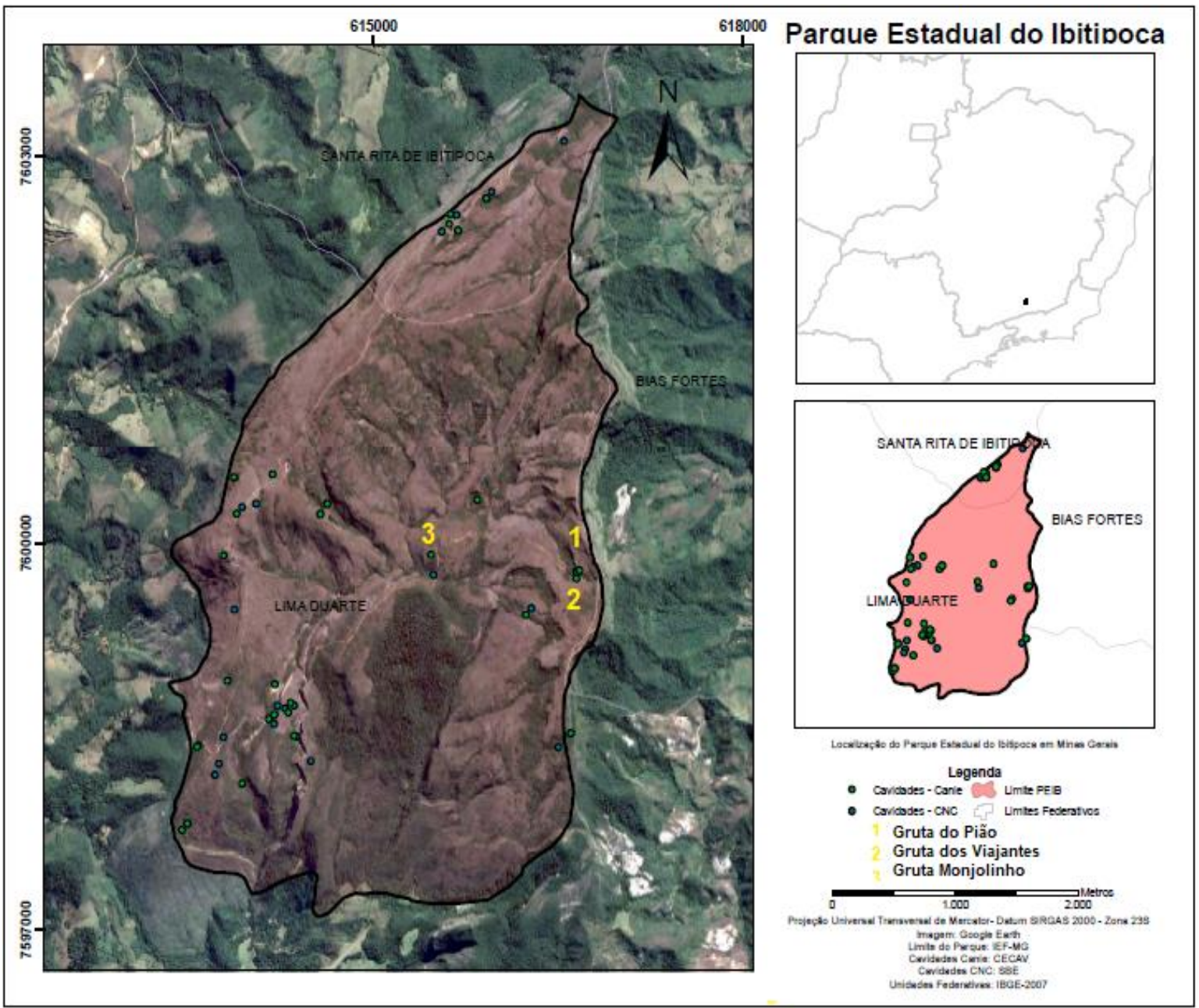

Figura 4: Mapa de localização, acesso e grutas do Parque Estadual do Ibitipoca (MG), com destaque para as grutas do Pião, dos Viajantes e Monjolinho. Fonte: Paulo Eduardo dos Santos Lima (2019).

Figure 4: Map of location, access and caves of Ibitipoca State Park (MG, Brazil) with emphasis on the

Pião, Travelers and Monjolinho caves. Source: Paulo Eduardo dos Santos Lima (2019).

\section{Materiais e Métodos}

A metodologia aplicada para avaliação do potencial espeleoturístico das grutas em questão foi adaptada do trabalho de Lobo (2007). O método em questão foi desenvolvido para análise do potencial espeleoturístico de cavernas carbonáticas e, conforme sugerido pelo próprio autor, foi adaptado para a realidade ambiental e turística do PEIB. Como o objetivo da pesquisa era a realização de uma pesquisa 
indicativa, cujos resultados possam contribuir para estudos aprofundados futuros, optou-se por analisar aspectos passíveis de análise visual/sensorial, tanto aqueles que fossem limitantes quanto os motivadores à visitação. De todos os indicadores existentes no método original, na análise realizada foram consideradas as categorias de fragilidades $(F)$, potencial geral $(P G)$ e potencial para contemplação (PC).

$\mathrm{Na}$ primeira etapa, foram realizadas três análises: fragilidades, potencialidades gerais - que indicam a aptidão da caverna para uso turístico - e potencialidades para o turismo de contemplação. As variáveis levantadas em campo são apresentadas nas Tabelas 1, 2 e 3).

Tabela 1: Fragilidades analisadas nas grutas do Circuito do Pião - PEIB (MG).

Table 1: Weaknesses analyzed in the caves of Pião Circuit - PEIB (MG, Brazil).

\section{FRAGILIDADES}

Grupo A - Fatores de Ordem Abiótica

A1 Apresenta possibilidade de desprendimentos espontâneos de rochas?

A2 Apresenta cursos ou corpos d'água em seu interior?

A3 Apresenta cursos d'água com possibilidades de enchentes repentinas?

A4 Apresenta desnível acentuado?

A5 Apresenta piso escorregadio?

A6 Os condutos não são suficientemente largos e altos para a passagem de pessoas (largura mínima: 1,50m; altura mínima: 1,90)?

A7 A gruta necessita do uso obrigatório de atividades e técnicas diferenciadas (rapel, escalada etc.)?

A8 Apresenta blocos instáveis no piso?

Grupo B - Fatores de Ordem Antrópica

B1 Foram encontrados pontos de degradação/depredações (pichações, fezes, lixo etc.)?

B2 É objeto de alguma pesquisa científica que possa inviabilizar o turismo?

B3 Apresenta espeleotemas sujeitos à dano físico pelo contato ou espeleotemas danificados?

B4 Apresenta vegetação sujeita à dano físico?

Grupo C - Fatores de Ordem Arqueológica/Paleontológica

C1 Apresenta vestígios paleontológicos/arqueológicos?

D1 Apresenta algum odor desagradável?

Grupo D - Fatores de Ordem Biótica

D2 Apresenta poças de guano?

Fonte: Diniz (2019), adaptado de Lobo (2007).

Source: Diniz (2019) adapted from Lobo (2007).

Tabela 2: Potencialidades gerais analisadas nas grutas do Circuito do Pião - PEIB (MG)

Table 2: General potentialities analyzed in the caves of the Pião Circuit - PEIB (MG, Brazil).

\section{POTENCIALIDADES GERAIS}

\begin{tabular}{ll}
\hline PG1 & $\begin{array}{l}\text { Distância do desvio da trilha principal do circuito até a entrada da gruta é superior à } 500 \\
\text { metros? }\end{array}$ \\
\hline PG2 & Distância do Centro de Visitantes até a entrada da gruta é superior à 2.000 metros? \\
\hline PG3 & Possui mais de uma entrada de fácil acesso? \\
\hline PG4 & Já apresenta trilha de acesso? \\
\hline PG5 & $\begin{array}{l}\text { Os condutos de acesso são suficientemente largos e altos para a passagem de pessoas } \\
\text { (largura mínima: 1,50m; altura mínima: } 1,90 m \text { )? }\end{array}$ \\
\hline PG6 & A gruta já é aberta à visitação? \\
\hline PG7 & $\begin{array}{l}\text { O possível trajeto de visitação é livre de dificuldades como: piso escorregadio, blocos } \\
\text { instáveis, travessia de água, substrato solto ou irregular? }\end{array}$ \\
\hline PG8 & Apresenta algum pórtico dotado de significativa beleza cênica? \\
\hline PG9 & Apresenta presença de lenda, folclore ou outra característica cultural associada à caverna? \\
\hline
\end{tabular}

Fonte: Costa (2019), adaptado de Lobo (2007).

Source: Costa (2019) adapted from Lobo (2007). 
Tabela 3: Potencialidades de contemplação analisadas nas grutas do Circuito do Pião - PEIB (MG).

Table 3: Potentialities of contemplation analyzed in the caves of the Pião Circuit - PEIB (MG, Brazil).

\section{POTENCIALIDADES DE CONTEMPLACÃO}

PC1 A cavidade apresenta amplos salões (volume de no mínimo $100 \mathrm{~m}^{3}$ e $3 \mathrm{~m}$ de altura)?

PC2 Apresenta algum espeleotema?

PC3 Apresenta vestígios paleontológicos/arqueológicos?

PC4 Apresenta claraboias?

PC5 Apresenta feições geológicas interessantes (dobras, veios, feições erosivas, diferenças litológicas etc.)?

PC6 Apresenta vegetação com beleza cênica?

PC7 Apresenta boa iluminação natural?

Fonte: Costa (2019), adaptado de Lobo (2007).

Source: Costa (2019) adapted from Lobo (2007).

Na metodologia aplicada no Parque Nacional da Serra da Bodoquena, no Mato Grosso do Sul (MS), foram definidas classificações de acordo com a somatória dos atributos por categorias considerando uma "pontuação base (peso um), adotada para todos os critérios analisados" (LOBO, 2007, p.105). A partir deste resultado, foram classificadas as fragilidades (Tabela 4), e potencialidades seguindo parâmetros baseados na quantidade de variáveis analisadas por categoria.

Tabela 4: Classificação da fragilidade ambiental espeleológica.

Table 4: Classification of speleological environmental fragility.

\begin{tabular}{cccc}
\hline & \multicolumn{3}{c}{ Grau geral de fragilidade } \\
\hline Baixa & Média & Alta & Absoluta \\
\hline $\begin{array}{c}\text { Até cinco } \\
\text { fragilidades } \\
\text { detectadas }\end{array}$ & $\begin{array}{c}\text { De seis a dez } \\
\text { fragilidades } \\
\text { detectadas }\end{array}$ & $\begin{array}{c}\text { Onze ou mais } \\
\text { fragilidades } \\
\text { detectadas }\end{array}$ & $\begin{array}{c}\text { Cavidade que apresente alguma } \\
\text { fragilidade cuja incompatibilidade com o } \\
\text { turismo tenha sido comprovada } \\
\text { cientificamente }\end{array}$ \\
\hline
\end{tabular}

Fonte: Lobo (2007).

Source: Lobo (2007).

Os parâmetros foram mantidos para a classificação das fragilidades das cavernas de Ibitipoca por apresentarem um número total avaliado muito próximo ao total de fragilidades avaliadas nas cavernas da Serra da Bodoquena. Entretanto, para as potencialidades, foram feitas adaptações proporcionais, por apresentarem números totais diferentes do trabalho referência (Tabela 5).

Tabela 5: Classificação da potencialidade espeleoturística das Cavernas do Circuito do Pião localizadas no PEIB (MG).

Table 5: Classification of the cave tourism potential of the Pião Circuit Caves located in PEIB (MG, Brazil).

Grau de Potencialidade Geral (PG)

\begin{tabular}{ccc}
\hline Baixa & Média & Alta \\
\hline $\begin{array}{c}\text { Entre uma e três } \\
\text { potencialidades detectadas }\end{array}$ & $\begin{array}{c}\text { Entre quatro e seis } \\
\text { potencialidades detectadas. }\end{array}$ & $\begin{array}{c}\text { Sete ou mais potencialidades } \\
\text { detectadas }\end{array}$ \\
\hline \multicolumn{2}{c}{ Grau de Potencialidade Contemplativa (PC) } & Alta \\
\hline Baixa & Média & Seis ou mais potencialidades \\
Entre uma e duas & Entre três e cinco & potencialidades detectadas. \\
\hline
\end{tabular}

Fonte: Costa (2019), adaptado de Lobo (2007).

Source: Costa (2019) adapted from Lobo (2007). 
Para obtenção dos resultados do potencial espeleoturístico das cavernas, adotou-se uma escala de valores (Tabela 6), com a finalidade de cruzar os dados das fragilidades e potencialidades e chegar à uma classificação final.

Tabela 6: Escala de valores para as fragilidades e potencialidades espeleoturísticas. Table 6: Scale of values weaknesses and potentialities for cave tourism.

\begin{tabular}{cccc}
\hline Grau de intensidade & Fragilidades & Potencial geral & Potencial para contemplação \\
\hline Baixa & 3 & 1 & 1 \\
\hline Média & 2 & 2 & 2 \\
\hline Alta & 1 & 3 & 3 \\
\hline Absoluta & 0 & - & - \\
& \multicolumn{4}{c}{ Fonte: Lobo (2007). } \\
& Source: Lobo (2007).
\end{tabular}

Seguindo o método de Lobo (2007), a obtenção da pontuação final da avaliação foi feita multiplicando-se a Fragilidade (F) pela soma das potencialidades geral (PG) e de contemplação (PC), resultando no Potencial Espeleoturístico Total (PET) da caverna analisada (Equação 1).

$$
P E T=F^{*}(P G+P C) * 100 / T
$$

Sendo: $F=$ fragilidades $; P G=$ potencial geral $P C=$ potencial para contemplação; $T=$ total de pontos possíveis considerando a escala utilizada.

A partir da equação apresentada, obtém-se o potencial espeleoturístico total da caverna, classificando as cavernas por classes de categoria de uso (Tabela 7).

Tabela 7: Análise final integrada do potencial espeleoturístico adaptada para as cavernas do PEIB (MG). Table 7: Final integrated analysis of the cave tourism potential adapted to the PEIB caves (MG, Brazil).

\begin{tabular}{ccc}
\hline Resultado (PET) & Classificação & Categoria de uso \\
\hline 84 a $100 \%$ & Absoluto & Classe A \\
\hline 68 a $83 \%$ & Intenso & Classe B \\
\hline 57 a $67 \%$ & Alto & Classe C \\
\hline 34 a $56 \%$ & Médio & Classe D \\
\hline 18 a $33 \%$ & Moderado & Classe E \\
\hline 1 a $17 \%$ & Baixo & Classe F \\
\hline $0 \%$ & Cavidade inapta ao turismo & Classe G \\
\hline
\end{tabular}

Fonte: Costa (2019), adaptado de Lobo (2007).

Source: Costa (2019) adapted from Lobo (2007).

Na aplicação realizada no PEIB, optou-se por dividir as cavernas em setores para que fossem gerados resultados em diferentes pontos das cavidades, além dos resultados gerais das cavernas. Essa setorização foi realizada para evitar que cavernas fossem avaliadas como inaptas ao turismo em sua totalidade, sendo que apenas alguns setores poderiam ser classificados nesta categoria.

A setorização das cavernas foi feita através de análises dos mapas espeleológicos, fichas de caracterização espeleológica, artigos científicos, e pelas experiências adquiridas anteriormente por espeleólogos integrantes da Sociedade Excursionista Espeleológica (SEE) em diversas etapas de campo nas cavernas do PEIB desde 2014, contribuindo para a elaboração desta metodologia. Foram fatores 
avaliados para a setorização: acessibilidade, iluminação, desenvolvimento, geomorfologia, bibliografia que abordasse fatores limitantes ou condicionantes à visitação turística em cavernas e recomendações do parque. Essas análises foram revistas durante a etapa de campo realizada entre os dias 8 e 10 de novembro de 2019, onde, confirmou-se ou não, a setorização previamente estabelecida.

\section{Resultados e discussão}

Inicia-se a exposição dos resultados pela gruta dos Viajantes. A gruta está inserida no Circuito Pico do Pião, um dos três circuitos turísticos do PEIB, sendo uma das cavernas mais volumosas do parque. Ademais, a gruta contém relevantes atributos que podem ser aproveitados turisticamente, apresentando grandes salões, vegetação de significativa beleza cênica e dois pórticos de fácil acesso. $\mathrm{Na}$ entrada principal da cavidade, já existem estruturas físicas implementadas para o acesso dos visitantes.

A necessidade de estudos para a manutenção da integridade da cavidade e para criação de medidas de segurança para os visitantes:

Os trabalhos de inspeção geomecânica, que identificam regiões de risco geotécnico, quedas de blocos e deslizamentos, não apontam perigo para visitantes (blocos soltos ou lajes na iminência de queda), no entanto as visitas devem ser feitas utilizando-se capacete e iluminação adequada devido ao comportamento imprevisível do maciço rochoso e assim evitar-se possíveis acidentes (LACERDA et al., 2017, p.274).

A cavidade, portanto, não apresenta indícios de instabilidade geológica. Porém, são necessários estudos mais detalhados contendo análises das condições hídricas, bem como de depósitos de sedimentos, e mesmo, de instabilidade de blocos, utilizando procedimentos adequados, podendo resultar em importantes informações para o parque, que deve controlar as visitações diárias à gruta, a fim de evitar ações indesejadas que podem comprometer a estabilidade do maciço.

Além disso, existe um conjunto cênico de pequenos espeleotemas na caverna, com três formas distintas: microtravertino, cortina serrilhada e escorrimento. Considerando estes e outros aspectos, chegou-se aos seguintes resultados para a gruta dos Viajantes:

-SETOR 1: Para o Setor 1, foram pontuados um total de: 3 fragilidades (baixa); 7 potencialidades gerais (alta) e 4 potencialidades de contemplação (média).

-SETOR 2: Para o Setor 2, foram pontuados um total de: 1 fragilidade (baixa); 6 potencialidades gerais (média) e 2 potencialidades de contemplação (baixa).

-SETOR 3: Para o Setor 3, foram pontuados um total de: 5 fragilidades (baixa); 5 potencialidades gerais (média) e 3 potencialidades de contemplação (média).

-SETOR 4: Para o Setor 4, foram pontuados um total de: 7 fragilidades (média); 5 potencialidades gerais (média) e 3 potencialidades de contemplação (média).

-SETOR 5: Para o Setor 5, foram pontuados um total de: 7 fragilidades (média); 7 potencialidades gerais (alta) e 5 potencialidades de contemplação (média).

- GERAL: A pontuação geral da alcançou a somatória de: 8 fragilidades (média); 7 potencialidades gerais (alta) e 6 potencialidades de contemplação (alta). 
Como resultado, a Gruta dos Viajantes obteve um PET de 67\%, sendo classificada como cavidade de potencial alto (Figura 5 ). Em relação aos PETs setorizados, destaca-se a classificação do Setor 1, que atingiu um resultado de $83 \%$, sendo classificado com potencial intenso. Desta forma, a gruta possui potencial alto para a visitação turística. Entretanto, sugere-se que a visitação ao atrativo seja periodicamente fiscalizada pela gestão do parque, bem como devem ser implementadas placas informativas contendo instruções de visitação à caverna. Tais medidas atendem às boas práticas de gestão do turismo em áreas protegidas, tais como sugerem os trabalhos de Marra (2001) e MTUR (2010).

Assim como as outras grutas do circuito, a gruta do Pião possui fácil acesso através de trilha bem marcada e sinalizada, o que explica em parte, a presença de pichações, lixos e dejetos humanos encontrados na cavidade. Além dessas formas de degradação/depredação, Lacerda et al. (2019, p.246) aponta indícios de instabilidade geológica na caverna, quando afirmam que "ultimamente, foi registrado através de visitantes e monitores ambientais do PEIB a ocorrência de possíveis rupturas de rocha, deslizamentos de blocos e desplacamentos de lajes no interior da gruta do Pião, que compromete a segurança da visita".

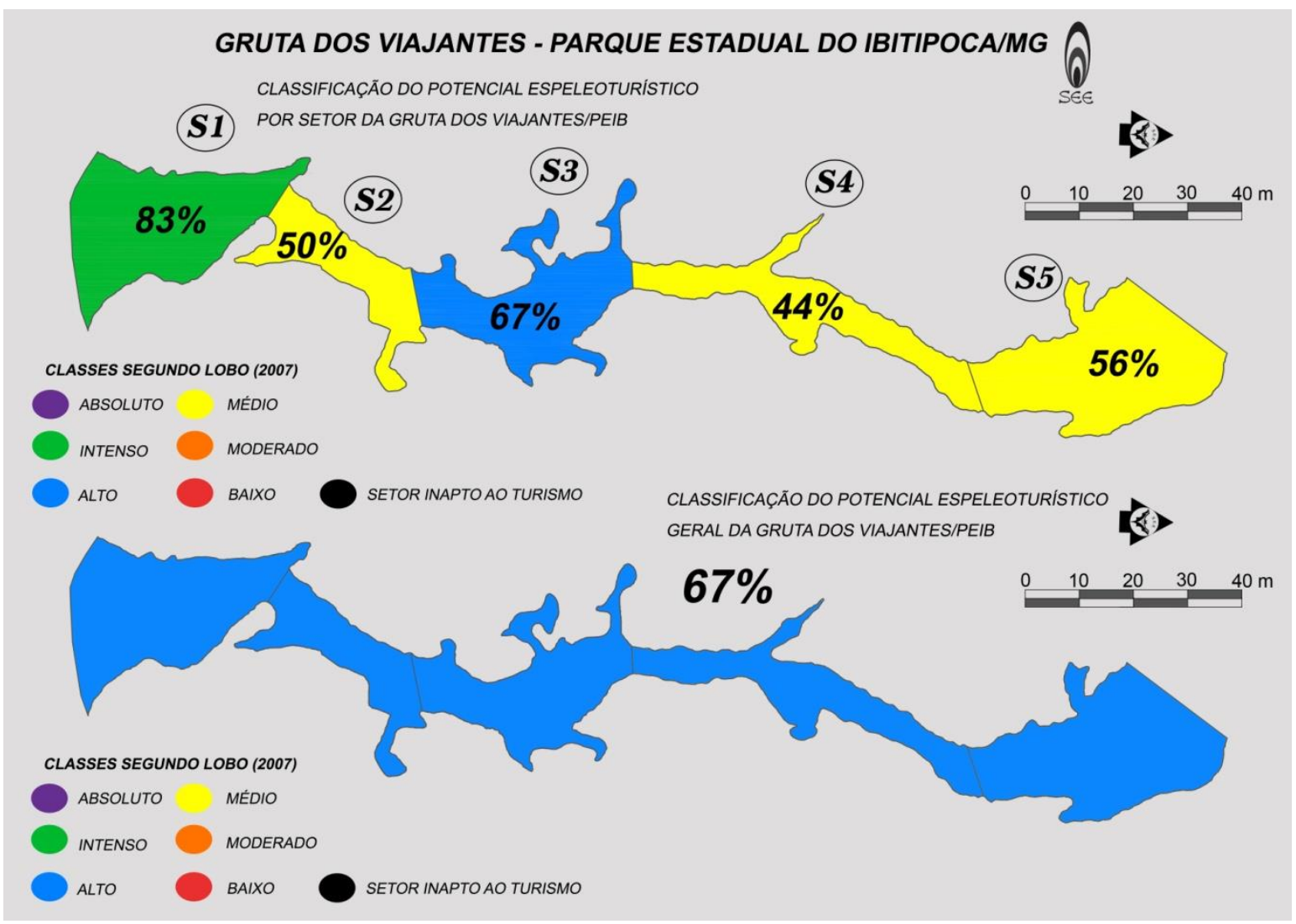

Figura 5: Potencial Espeleoturístico geral da gruta dos Viajantes, PEIB (MG).

Figure 5: General Cave Tourism Potential of the cave of Travelers, PEIB (MG, Brazil).

Fonte: Costa (2019).

Source: Costa (2019).

Além da instabilidade geomecânica apontada no Setor 3 da gruta, o uso indevido da cavidade também foi considerado para a interpretação dos resultados de potencial espeleoturístico. A partir das variáveis observadas em campo, chegou-se aos seguintes resultados na gruta do Pião: 
-SETOR 1: Para o Setor 1, foram pontuados um total de: 4 fragilidades (baixa); 7 potencialidades gerais (alta) e 2 potencialidades de contemplação (baixa).

-SETOR 2: Para o Setor 2, foram pontuados um total de: 6 fragilidades (média); 4 potencialidades gerais (média) e 0 potencialidades de contemplação (baixa).

-SETOR 3: Para o Setor 3, foram pontuados um total de: 6 fragilidades (média); 5 potencialidades gerais (média) e 2 potencialidades de contemplação (baixa).

-SETOR 4: Para o Setor 4, foram pontuados um total de: 7 fragilidades (média); 5 potencialidades gerais (média) e 2 potencialidades de contemplação (baixa).

- GERAL: A pontuação geral da caverna alcançou a somatória de: 9 fragilidades (média); 6 potencialidades gerais (média) e 5 potencialidades de contemplação (média).

Pelo resultado do PET setorizado, percebe-se que apenas a entrada da gruta teria potencial considerável para visitação turística. Porém, se analisarmos o PET geral, a gruta apresenta potencial espeleoturístico médio, atingindo a pontuação de 44\% (Figura 6). Dessa forma, considera-se que as avaliações setorizadas apresentam um potencial mais próximo da realidade do que as gerais neste caso, oferecendo um panorama mais específico do setor avaliado.

A gruta do Monjolinho é a primeira gruta do Circuito do Pião, a aproximadamente 2.000 metros do Centro de Visitantes do PEIB. A cavidade considerada para este estudo, serve como passagem para um outro atrativo que muito provavelmente, se trata de feição homônima apresentada por IEF (2006). Por ser local de passagem dos visitantes, a depredação é bastante considerável, além da cavidade ser utilizada como banheiro, considerando os vários dejetos humanos encontrados em seu interior. Para a gruta do Monjolinho, chegou-se aos seguintes resultados:

-SETOR 1: Para o Setor 1, foram pontuados um total de: 1 fragilidade (baixa); 7 potencialidades gerais (alta) e 2 potencialidades de contemplação (baixa).

-SETOR 2: Para o Setor 2, foram pontuados um total de: 3 fragilidades (baixa); 5 potencialidades gerais (média) e 0 potencialidades de contemplação (baixa).

-SETOR 3: Para o Setor 3, foram pontuados um total de: 1 fragilidade (baixa); 6 potencialidades gerais (média) e 0 potencialidades de contemplação (baixa).

-SETOR 4: Para o Setor 4, foram pontuados um total de: 3 fragilidades (baixa); 4 potencialidades gerais (média) e 0 potencialidades de contemplação (baixa).

- GERAL: A pontuação geral da caverna alcançou a somatória de: 6 fragilidades (média); 7 potencialidades gerais (alta) e 2 potencialidades de contemplação (baixa).

Como resultado, a gruta do Monjolinho obteve um PET de 44\%, sendo classificada como cavidade de potencial médio (Figura 7). Conclui-se que a cavidade somente não obteve um PET inferior, por obter alta pontuação nas potencialidades gerais e por não utilizar diferentes pesos para as fragilidades, a depender de sua intensidade e/ou quantidade.

Nota-se também a necessidade de relativizar e contextualizar a aplicação do método de análise de potencial espeleoturístico quando de sua aplicação fora do contexto de rochas carbonáticas. Ocorre que o método foi desenvolvido para uma 
condição ambiental de carste clássico, no qual os fenômenos de dissolução e deposição de minerais governam a modelagem do relevo (TRAVASSOS, 2019). Por consequência, tais processos geram padrões e formas de relevo que sob a ótica da contemplação, são variados, inusitados e instigam a curiosidade dos visitantes (MARRA, 2001; LOBO, 2007; LOBO, 2014).

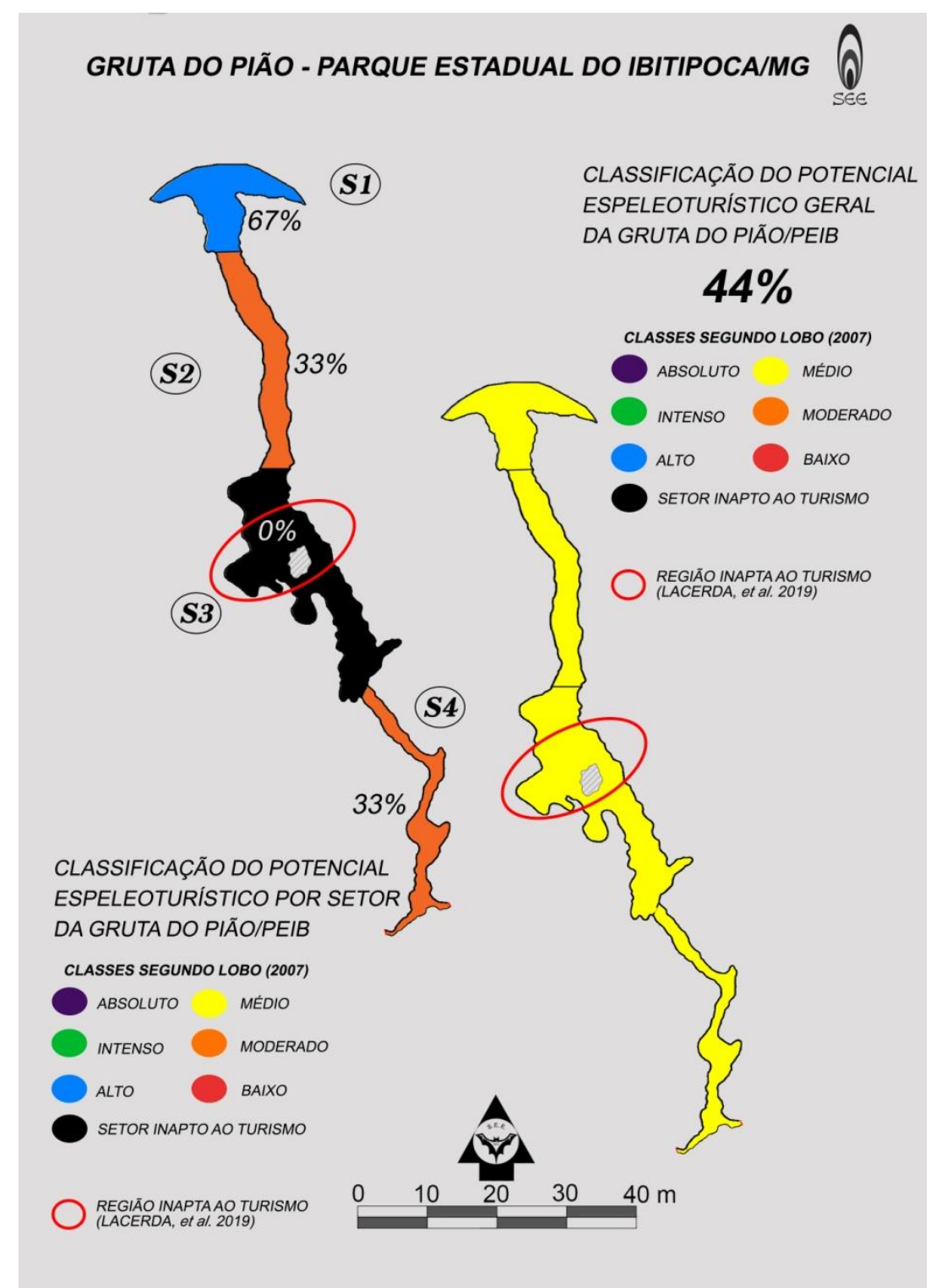

Figura 6: Potencial Espeleoturístico geral da gruta do Pião, PEIB (MG).

Figure 6: General Cave Tourism Potential of cave of Pião, PEIB (MG, Brazil).

Fonte: Costa (2019).

Source: Costa (2019).

Este mesmo aspecto não se verifica em igual forma e abundância em uma paisagem composta por quartzitos (HARDT; PINTO, 2009), como o caso estudado. No entanto, entende-se que a curiosidade do visitante permanece, talvez pelo fascínio que as cavernas exercem nas pessoas ou mesmo movidos pela curiosidade pelo desconhecido. A própria existência de visitação constante nas cavernas pesquisadas evidencia este aspecto, de modo que cavernas com baixo potencial turístico podem ser ainda assim interessantes aos visitantes, em função do contexto regional em que estão inseridas. 


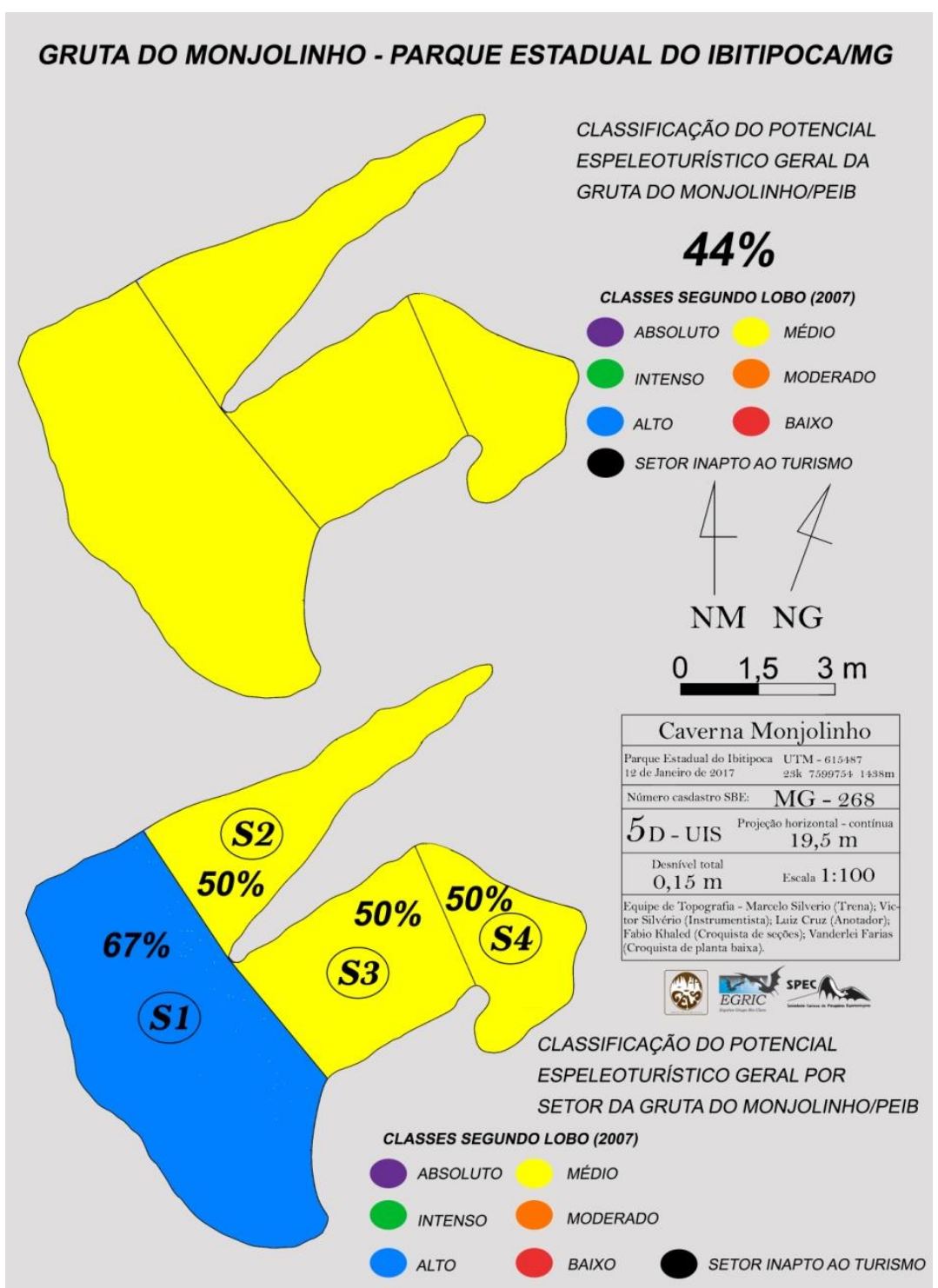

Figura 7: Potencial espeleoturístico geral da gruta Monjolinho, PEIB (MG).

Figure 7: General cave tourism potential of cave of Monjolinho, PEIB (MG, Brazil).

Fonte: Costa (2019).

Source: Costa (2019).

\section{Considerações Finais}

De um modo geral, constata-se a aplicabilidade da metodologia proposta neste trabalho, onde foi possível gerar resultados técnicos similares às percepções e avaliações realizadas em atividade de campo. Observou-se a necessidade de rediscutir, em estudos futuros, o conceito de fragilidade e sua aplicação no contexto de cavernas em diferentes tipos de rochas, bem como a sua relação com o estado de conservação do ambiente. Essa nova percepção levanta uma possível recategorização das variáveis, tendo em vista que o presente trabalho foi a primeira tentativa de adaptação do método para as cavernas do PEIB.

Para efetivação do método, são ainda necessárias análises mais aprofundadas para os fatores de ordem biótica e atmosférica e criação de variáveis para estas categorias, que por sua vez, constituem papel fundamental na viabilização ou não do turismo. Além dos impactos já esperados pelas movimentações turísticas em larga escala, é possível observar inúmeras alterações 
antrópicas que comprometem a integridade natural das grutas. Apesar da gruta dos Viajantes também apresentar impactos gerados pela visitação turística, percebe-se que as grutas do Pião e Monjolinho possuem mais pontos de degradação e/ou depredação, necessitando de medidas de proteção mais urgentes.

Vale destacar que além da avaliação do potencial espeleoturístico das cavernas turísticas do PEIB, alterações no modelo de visitação do parque podem e devem ser realizadas. Diante da necessidade eminente de um modelo que contemple preferencialmente a conservação dos atributos naturais do Parque conciliadas com um turismo mais sustentável, sugere-se a realização de estudos de capacidade de suporte que tragam resultados mais efetivos sobre os limites numéricos e comportamentais - para uso dos diversos roteiros, além das cavernas.

A conservação do ambiente, em especial as cavernas, depende também do ordenamento turístico, que é possibilitado pela efetividade da gestão e por meio de programas de sensibilização ambiental, interpretação do patrimônio natural, capacidade de carga, zoneamento espeleológico e a discussão sobre serviços de condução ambiental. Com isso, a gestão do parque poderá elaborar diretrizes de ordenamento do turismo nas cavidades, contribuindo com sua efetiva conservação e com seu uso responsável.

\section{Agradecimentos}

Os dados do presente artigo fazem parte do trabalho de conclusão de curso (orientado pelos coautores) e iniciação científica do primeiro autor. Os autores agradecem à Sociedade Excursionista \& Espeleológica e seus membros pela contribuição nas etapas de escritório e de campo; à Universidade Federal de Ouro Preto e Universidade Federal de São Carlos - Campus Sorocaba, pelo apoio; à GPROP/IEF pela licença de pesquisa em unidade de conservação (PEIB 41/2019); ao Parque Estadual do Ibitipoca pelo suporte de campo e alojamento; ao Prof. Paulo de Tarso Amorim Castro pela orientação no Projeto "Cadastro e Avaliação dos Aspectos Espeleoturísticos das Cavernas do Parque Estadual do Ibitipoca, Minas Gerais"; e aos pareceristas e editores da Revista Brasileira de Ecoturismo pelas contribuições para melhoria do artigo.

\section{Referências}

BRASIL Lei no 9.985, de 18 de julho de 2000. Brasília: Ministério do Meio Ambiente, 2000.

CECAV. Cadastro Nacional de Informações Espeleológicas. 2019. Disponível em: <http://www.icmbio.gov.br/cecav/canie.html>. Acesso em: 21 jan. 2020.

CERVANTES, C. A. Las cuevas en la historia de la humanidad. In: TRAVASSOS, L. E.P.; MAGALHÃES, E.D.; BARBOSA, E.P. Cavernas, rituais e religião. Ilhéus, BA: Editus, p. 21-48.

CNC. Cadastro Nacional de Cavernas. 2019. Disponível em: <http://www.cavernas.org.br/cnc/>. Acesso em: 21 jan. 2020.

COSTA, B.D. Avaliação do potencial espeleoturístico das grutas do Circuito do Pião, Parque Estadual do Ibitipoca - MG. 2019. 93f. Monografia (Bacharelado em Turismo). Universidade Federal de Ouro Preto. 2019. 
DIEGUES, A.C.S. O mito moderno da natureza intocada. São Paulo: Hucitec, 2001. $102 \mathrm{p}$.

HARDT, R.; PINTO, S.A.F. Carste em litologias não carbonáticas. Revista Brasileira de Geomorfologia, v.10, n.2, p. 99-105, 2009.

IEF. Plano de Manejo Parque Estadual do Ibitipoca: Relatório do Diagnóstico de Uso Público. Belo Horizonte: IEF, 2006.

IEF. Acordo possibilita aumento de visitantes no Parque Estadual do Ibitipoca. 2019. Disponível em: <http://www.ief.mg.gov.br/noticias/2755-acordo-do-ief-com-mppossibilita-aumento-de-visitantes-no-parque-estadual-do-ibitipoca->. Acesso em: 07 jan. 2021.

LACERDA, S.G. et al. Caracterização geomecânica do maciço rochoso da Gruta do Pião - Parque Estadual do Ibitipoca, Minas Gerais. CONGRESSO BRASILEIRO DE ESPELEOLOGIA, 35, 2019. Bonito. Anais... Campinas: SBE, 2019. p. 244-252. Disponível em: <http://www.cavernas.org.br/anais35cbe/35cbe 244-252.pdf>. Acesso em: 07 jan. 2021.

LACERDA, S.G. et al. Caracterização geomecânica do maciço rochoso da Gruta dos Viajantes, Parque Estadual do Ibitipoca, sudeste de Minas Gerais. Anais... Congresso Brasileiro de Espeleologia, Ouro Preto (MG). p. 261-275, 2017.

LADEIRA, A.S. et al. O perfil dos visitantes do Parque Estadual do Ibitipoca (PEIB), Lima Duarte, MG. Revista Árvore, v. 31, n. 6, p. 1.091-1.098, 2007.

LOBO, H.A.S. Método para avaliação do potencial espeleoturístico do Parque Nacional da Serra da Bodoquena, MS. Caderno Virtual de Turismo, v. 7, n. 3, p. 99-110, 2007.

LOBO, H.A.S. Fundamentos básicos do espeleoturismo. Dourados: UEMS, 2014. $179 \mathrm{p}$.

LOBO, H.A.S.; PERINOTTO, J.A.J.; BOGGIANI, P.C. Espeleoturismo no Brasil: Panorama geral e perspectivas de sustentabilidade. Revista Brasileira de Ecoturismo, v. 1, n. 1, 2008.

MARRA, R.J.C. Espeleoturismo: Planejamento e manejo de cavernas. Brasília: WD Ambiental, 2001.

MINAS GERAIS. Lei no 6126, de 4 de julho de 1973. Cria os Parques Florestais de Ibitipoca e da Jaíba, nos municípios de Lima Duarte e Manga. Belo Horizonte: Assembleia Legislativa de Minas Gerais, 1973.

MTUR Ecoturismo: orientações básicas. Brasília: Ministério do Turismo, 2010.

OSTANELLO, M.C.P.; DANDERFER, A.; CASTRO, P.T.A. Caracterização de lugares de interesse geológico e trilhas geoturísticas no Parque Estadual do Itacolomi - Ouro Preto e Mariana, Minas Gerais. Geociências UNESP, v. 32, n. 2, p. 286-297, 2013.

RUSCHMANN, D.M. Turismo e planejamento sustentável: a proteção do meio ambiente. Campinas, SP: Papirus editora, 2016.

TRAVASSOS, L.E.P. Princípios de carstologia e geomorfologia cárstica. Brasília: ICMBio, 2019. 242 p. 
Bruno Diniz Costa: Universidade Federal de Ouro Preto, Ouro Preto, MG, Brasil E-mail: brunodinizespeleo@gmail.com

Link para o currículo Lattes: http://lattes.cnpq.br/6897792369316693

Ricardo Eustáquio Fonseca Filho: Universidade Federal de Ouro Preto, Ouro Preto, MG, Brasil

E-mail: ricardo.fonseca@ufop.edu.br

Link para o currículo Lattes: http://lattes.cnpq.br/1600424426811223

Heros Augusto Santos Lobo: Universidade Federal de São Carlos, Sorocaba, SP, Brasil

E-mail: heroslobo@ufscar.br

Link para o currículo Lattes: http://lattes.cnpq.br/9405961078398915

Data de submissão: 04 de fevereiro de 2020

Data de recebimento de correções: 20 de outubro de 2020

Data do aceite: 20 de outubro de 2020

Avaliado anonimamente 